University of Nebraska - Lincoln

DigitalCommons@University of Nebraska - Lincoln

3-27-2019

\title{
Resource Management in a Time of Fiscal Scarcity: Combining Qualitative and Quantitative Assessment for Journal Package Cancellations
}

Casey D. Hoeve

University of Nebraska-Lincoln, achoeve@unl.edu

Follow this and additional works at: https://digitalcommons.unl.edu/libraryscience

Part of the Collection Development and Management Commons

Hoeve, Casey D., "Resource Management in a Time of Fiscal Scarcity: Combining Qualitative and Quantitative Assessment for Journal Package Cancellations" (2019). Faculty Publications, UNL Libraries. 398.

https://digitalcommons.unl.edu/libraryscience/398

This Article is brought to you for free and open access by the Libraries at University of Nebraska-Lincoln at DigitalCommons@University of Nebraska - Lincoln. It has been accepted for inclusion in Faculty Publications, UNL Libraries by an authorized administrator of DigitalCommons@University of Nebraska - Lincoln. 


\title{
Resource Management in a Time of Fiscal Scarcity: Combining Qualitative and Quantitative Assessment for Journal Package Cancellations
}

\author{
Casey Daniel Hoeve \\ Kansas State University, Manhattan, Kansas, USA \\ Contact: Casey Daniel Hoeve, University Libraries, University of Nebraska-Lincoln, \\ 317 LLS, 68588-4100; achoeve@unl.edu \\ ORCID - Casey Daniel Hoeve http://orcid.org/0000-0003-4837-8910
}

\begin{abstract}
As a result of continual resource inflation and a decreasing budget, Kansas State University Libraries were required to conduct a large-scale electronic journal cancellation project. The current organizational model does not require librarian subject specialists to perform comprehensive collection development duties; therefore, content development librarians developed a methodology of collecting quantitative and qualitative statistics to collaboratively evaluate journals. This article will demonstrate the methodology of assessment, and serve as a working model for libraries operating under circumstances of labor shortages, budget cuts, and leadership restructuring.
\end{abstract}

Keywords: Library, assessment, journals, serials, budget, cancellation, package

Published in The Serials Librarian 75 (2019), pp 42-50.

DOI: 10.1080/o361526X.2019.1576571

Copyright (c) 2019 Casey Daniel Hoeve; published by Routledge/Taylor \& Francis.

Used by permission.

Published 27 March 2019. 


\section{Introduction}

Kansas State University is a Doctoral Research, Highest Research Activity (R1) University as designated by the Carnegie Classification of Institutions of Higher Education. ${ }^{1}$ As the first university established under the Morrill Act, and the oldest public institution of higher learning in Kansas, Kansas State University Libraries (K-State Libraries) serve a population of over 20 , 000 students and faculty combined, providing access to resources supporting curriculum and research needs.

In the last decade, the State of Kansas has imposed more than $\$ 100$ million dollars in budget cuts to higher education. ${ }^{2}$ During the same period, K-State Libraries operated under a flat budget until 2014, followed by significant budget cuts enacted by the university. Resource inflation by vendors ${ }^{3}$ further contributed to a reduction in purchasing power, with the Libraries experiencing over $\$ 800,000$ in decreased collections allocations, accounting for $55 \%$ of the Libraries' cumulative budget reduction-cuts of more than $\$ 285$, ooo annually are anticipated to keep pace with inflation. Recent changes to the university budget model, now adopting Responsibility Centered Management $(\mathrm{RCM})$, focus on revenue and expenditure management by revenuedriven departments. This model directly benefits departments and programs with high enrollment, at the expense of smaller departments and general education courses. ${ }^{4}$ As the Libraries are considered a nonrevenue- generating campus "utility" under the RCM model, such practices subsequently separate the Libraries from academic unit funding, implicitly meaning decreased monetary support for the Libraries. The combination of funding reductions has necessitated largescale resource cancellations to balance the Libraries' budget.

In 2017, the Associate Dean for Technical Services and Scholarly Communications retired, and the Head of Content (Collection) Development accepted a new position at another academic institution. Serving as a temporary solution, the Content Development Unit was ingested by the Academic Services Department (Figures 1 and 2), merging content development librarians together with subject specialist librarians. Under the current management model at K-State Libraries, subject specialist librarians provide ad hoc assistance in the annual review of select resources, but do not perform collection development duties on a regular basis. In the absence of 


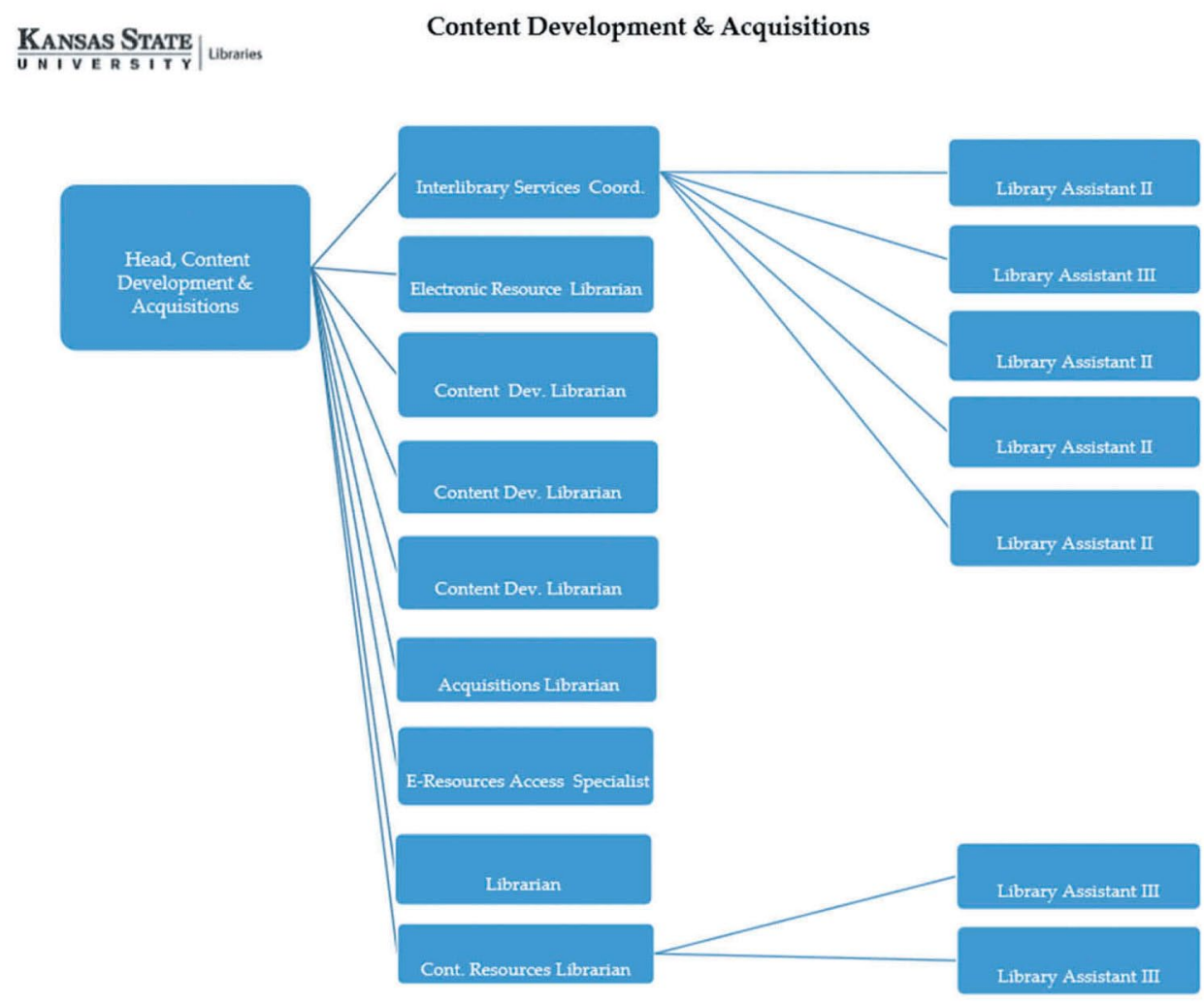

Figure 1. Content development and acquisitions department (previous organizational model).

content development administrative guidance, the content development librarians were charged with leading resource reviews and cancellations.

Given the sizeable targeted cut of $\$ 285,000$ for the fiscal year, it was concluded that a wider range of participation and transparency was paramount to successfully balancing the Libraries' collections budget. Therefore, the content development librarians created a project plan incorporating qualitative and quantitative statistics to assess journal packages selected for potential cancellation.

\section{Methodology}

A fire in Hale Library on May 22, 2018, caused a significant delay in the process of annual reviews. The library was deemed a total loss. 


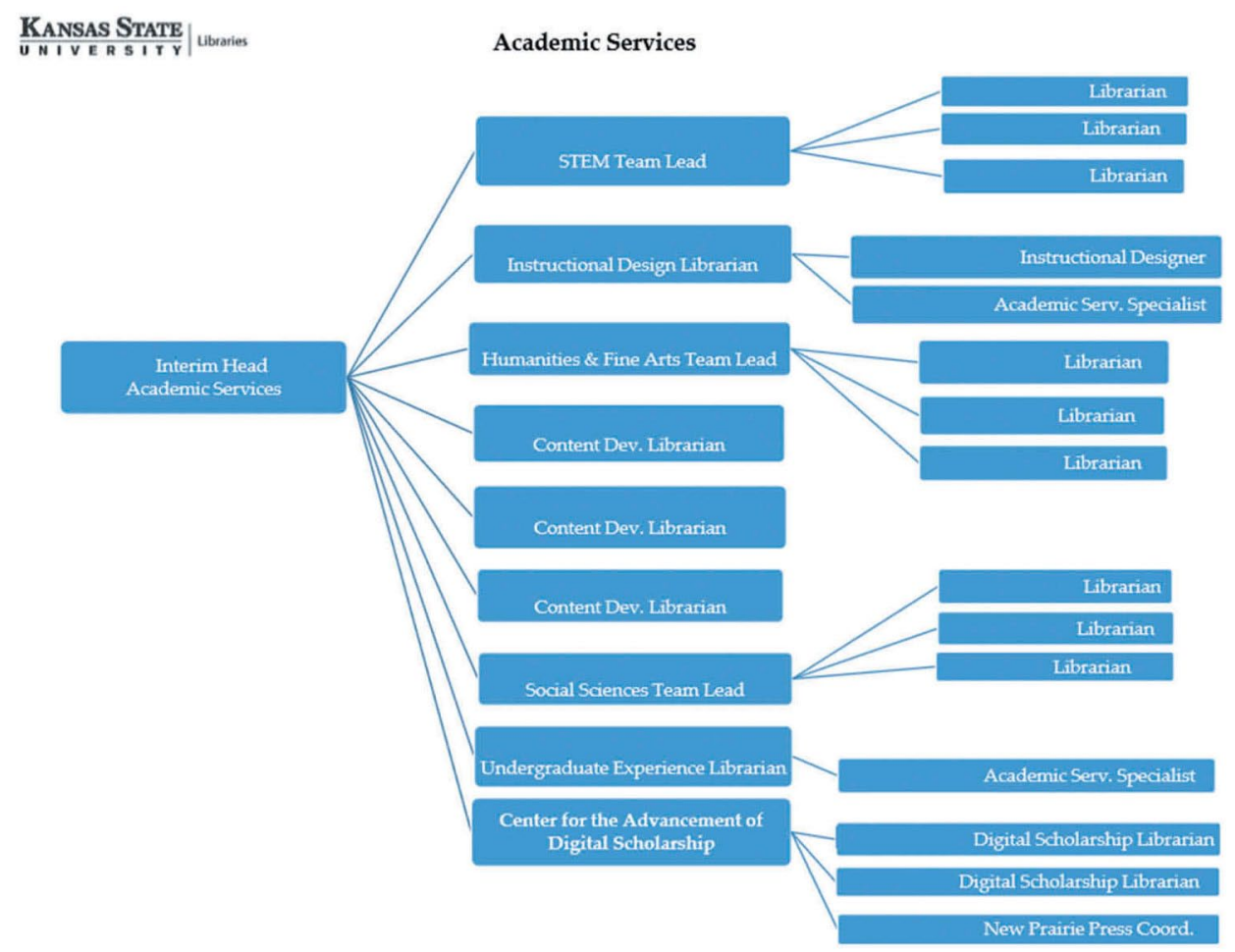

Figure 2. Content development ingested into academic services department (new organizational model).

Time devoted to librarian and staff relocation, and the restoration of information technology services postponed journal package evaluations by nearly one month. Finalized decisions were requested from our subscription agent Harrassowitz ${ }^{5}$-who generously extended our deadline-by the beginning of September, thereby ensuring effective collaboration with the Continuations and Serials Unit to process invoices. Within this limited duration, adequate time was also required for librarians and department faculty to review journals before the fall semester. ${ }^{6}$

Time and labor shortages reflected the need to establish an expedited project plan to conduct a thorough examination of the following journal packages: Oxford University Press, Cambridge University Press, University of Chicago Press, Duke University Press, Brill, and Mathematical Science Publishers. Journal packages rather than databases, monographs, and other resources were selected for review, as they were the first products to be potentially renewed or cancelled at the beginning of the fiscal year and would have the greatest impact 
on early budget savings and forecasting. In addition, some of K-State Libraries' more expensive resources were unable to be reviewed, being protected under multiyear deals, thus the Libraries were contractually obligated to renew those resources.

In a basic cost analysis of subscription prices for the next fiscal year, it was concluded that keeping or cancelling entire journal packages would not successfully balance the budget and provide adequate access to research materials for faculty and students. Therefore, it was decided that all packages would need to be broken apart, and journals would be subscribed to on an individual basis, thus creating a cluster of individual subscriptions by publisher.

The proceeding steps outline the processes used to successfully combine qualitative and quantitative data ${ }^{7}$ for the purpose of evaluating journal packages, and suggestions for improvement to use this methodology for reviewing additional library resources (e.g., databases, streaming media, monographs) in the future through a more systematic approach as devised in this case study.

\section{Assessment}

A large proportion of collection assessment is completed by the Content Development Unit, particularly concerning annual renewal decisions of databases and journals. Previously, Content Development Librarians combined cost-per-use analyses and subject expertise to renew or cancel resources. When large disparities in price increases or low usage occurred, Content Development Librarians would meet with Academic Service Librarians (subject specialists) to liaison with departments and determine whether a resource renewal was justified.

The incorporation of the Content Development Unit into the Academic Services Department produced opportunities for frequent interactions between technical services and subject librarians and established a shared vision of increased participation and communication. A greater investment in collaboration was intended to educate subject specialists on the process of evaluation, and likewise, further inform content development librarians on the contextual use of resources. This process additionally garnered support to maintain positive relationships with department faculty, and improve methods for transparent communication and feedback during unpopular cancellation projects. 
Within the current organizational model at K-State Libraries, the majority of subject specialists do not possess collection development experience. To overcome this obstacle, a department meeting was held, specifically devoted to teaching the basics of qualitative and quantitative metrics used by content development librarians. Areas of teaching focused on usage, cost, accreditation standards, and curriculum and research support. This instructional session served as the basis for establishing preparations for evaluating major journal packages.

\section{Quantitative assessment}

The Content Development Unit was responsible for gathering the quantitative statistics for the review process. Several positions in the unit remained unfilled due to budget reductions, so tasks were performed by a combination of content development librarians, displaced staff as a result of the library fire (when time allowed), and part-time student workers. Staff and students were provided with formal training on transferring and calculating data on spreadsheets and reported to content development librarians for further instruction as needed.

During the initial phase of quantitative assessment, a list of subscribed journals, separated by package, was obtained from the KState Libraries' subscription agent. This spreadsheet contained bibliographic information for each journal and became the working document for tracking and evaluating quantitative data. Additional columns were added to the spreadsheet to include usage data, cost, and access options.

Usage data were exported from administrator portals of vendor websites. When possible, usage data were obtained for three prior years, in addition to the current year. The current year was defined as the timeframe spanning six months from January-June, and usage data were extrapolated for the full year by doubling ${ }^{8}$ the number of uses. These data were populated on the spreadsheet and calculated to generate the average use of each journal over four years.

Journal cost was collected through several means. In many cases, list prices for journals were obtained through vendor websites or by consulting Ulrich's Periodicals Directory. In circumstances when journal costs were not available, estimates were able to be provided based on predicted inflation forecasts ${ }^{9}$ by scholars or subscription agents. 
Given the limited timeframe to complete the project, average journal costs over a period of four years could not be readily obtained. Cost per use was therefore calculated on the spreadsheet by dividing the current list price by average use.

In nearly all packages examined, K-State Libraries retained electronic perpetual access from the beginning subscription date to the current year. Access options for each journal were determined by searching by title in the Libraries' local catalog and discovery service, noting direct access through publishers, as well as alternative access in databases and aggregators. Full-text access years (including embargoes and subscription gaps), providers, and products were populated on the spreadsheet corresponding to each journal.

The spreadsheet allowed librarians to sort and filter data to identify journals with low use or a high cost per use, in addition to identifying duplicate (yet non-perpetual) access through databases and aggregators. From the gathered and sorted data, an average usage threshold was recommended, initially identifying journals for retention or potential cancellation to balance the collections budget. Journal titles above the threshold were automatically approved for renewal, whereas the journals below the threshold were marked for potential cancellation. As use varies dramatically by subject and type of material, ${ }^{10}$ science journal usage was often higher than social sciences and the humanities. Working with Libraries Administration, it was agreed that the aforementioned issue must be considered in the evaluation process, and that the targeted budget cut would not be attained solely through raw usage data. Other considerations such as cost per use and qualitative values would prove essential for conducting a comprehensive evaluation that was fair and representative of all fields, departments, and subjects.

\section{Qualitative assessment}

The second part of the evaluation consisted of qualitative assessment, which sought to establish a transparent method for informing faculty and students about the cancellation project. The Content Development Unit collaborated with Libraries Administration and the Libraries Communications and Marketing group to develop an announcement for K-State Today, ${ }^{11}$ the daily university newsletter. The announcement informed faculty and students about the budget status 
of the Libraries, and invited optional participation in the evaluation process by inviting feedback on the list of journals identified for potential nonrenewal.

To gather qualitative feedback, the Content Development Unit used Qualtrics to develop a survey for each journal package. Survey fields consisted of the following information: Name, Department, Email, Journal Title(s), and Comments. Each survey could be exported to a CSV, TSV, XML, or SPSS file for data analysis. For this particular project, CSV files were used, as they were the most familiar to Libraries faculty. The surveys were made available for a duration of five weeks, allowing for enough time to analyze and review data, and make renewal decisions before the September deadline.

To ensure greater transparency, content development and subject librarians reached out to their respective subject department heads, alerting them to the cancellation project announcement. It was requested that the department heads send additional e-mails to their faculty to increase awareness of the situation, and to encourage them to provide feedback on the surveys. As an additional measure, followup e-mails were sent to department heads within a week to confirm dissemination of the information.

In the ensuing correspondence, librarians asked faculty to provide specific reasons in the surveys for retaining journals, including but not limited to: need for program accreditation, information literacy instruction (for library faculty), contribution to K-State's 2025 strategic goals, and essential journals to support the curriculum and faculty research. This information was collected in the "Comments" section of the survey. Communication between department faculty and librarians continued during the review window, clarifying any questions or concerns about the process.

\section{Compiling data and decision making}

The generation of a holistic review required the combination of quantitative and qualitative data to make informed decisions. The Content Development Unit initially organized all qualitative data. Over 137 faculty members responded to the surveys ( $9.88 \%$ response rate), ${ }^{12}$ commenting on more than 900 journals (many of which were duplicate titles). Merging all qualitative surveys into a single spreadsheet, and then sorting journals by title and publisher (Appendix) added 
significant value to the review process; librarians could view multiple retention requests for a specific title, and determine if the journal was central to one or multiple departments. The Content Development Unit then proceeded to combine qualitative and quantitative spreadsheets, generating a comprehensive assessment of data collection and presentation.

The synthesized spreadsheet was uploaded to Google Drive, and permissions to view and edit the spreadsheet were limited to subject specialists and content development librarians. Columns were added to the spreadsheet for "Decisions" and "Notes." Librarians were given a week to review the titles and data, and make the recommendation "Keep" for a journal to be reconsidered for retention. Any journal title with a blank decision field was considered cancelled. Only journals labeled as "Keep" would be reviewed for potential retention at the final decisions meeting.

The final decisions meeting was scheduled at the end of the oneweek review period. Librarians served as the ultimate arbiters of journal retention. Within the meeting, the following issues were discussed before making a decision about a journal:

(1) Concerns about the accuracy of usage statistics and how vendors determine a use. ${ }^{13}$ It was agreed that this was a starting point for reviewing journals, and additional factors should be taken into account when making final decisions.

(2) Variations in usage statistics due to department size, reading habits of subject faculty, and the type of material. ${ }^{14}$ These variables were taken into consideration to ensure fair evaluation across all disciplines.

(3) The cost-benefit analysis of keeping subscriptions versus interlibrary loan access. ${ }^{15}$ Librarians attempted to cancel journals with extremely high cost per use, but due to the extent of the targeted cuts, some journals with a cost per use slightly below the borrowing fee had to be cancelled.

(4) Cancellation of a journal with full-text access or a short-term embargo in an aggregator. ${ }^{16}$ Cancelling a journal in an aggregator was not viewed as an optimal solution, but it was decided that it was an acceptable risk and alternative substitution in order to retain a greater number of journals. 
During the session, cancelled journals were highlighted in yellow, and impasse journals (potentially cancelled) were highlighted in blue. After the conclusion of the meeting, the content development librarians calculated the number of journals recommended for cancellation and the amount to be cut (or money saved) from the budget.

\section{Results of the review}

Initial calculations determined that the list of yellow (cancelled) and blue (impasse decision- potentially cancelled) titles did not meet the anticipated amount to balance the budget. Combined with resource cancellations near the end of the prior fiscal year, additional resource cuts were needed to meet the $\$ 285$, ooo target goal. The Content Development Unit and Acquisitions Unit convened with Libraries Administration, concluding that:

(1) All yellow and blue highlighted would be cut.

(2) A small amount of the Libraries funds could be shifted toward collection costs.

(3) A portion of monograph allocations would need to be cutt7

Decisions 1-3 would allow the Libraries to balance the collections budget.

It was further decided that additional resource reviews should be conducted and appropriate cancellations should be made throughout the fiscal year; depending on the extent and amount of these cuts, it was suggested that monograph funds could be restored to the full amount. As a caveat, it was expressed that additional recall of funds issued by the state, budget reductions by the university, or a higher predicted inflation rate could result in conducting another major cancellations project.

As a result of the assessment, over 490 journals (approximately $67 \%$ ) were cancelled, with a reduction totaling $\$ 128,608.39$ to date. It is anticipated that these numbers will increase as reviews occur throughout the fiscal year. All packages except one were broken apart, with the Libraries choosing to subscribe to a smaller selection of titles from the former packages. In one case, a publisher worked with the Libraries to restructure a favorable deal, enabling the Libraries to 
keep the journal package and provide access to a greater number of titles. To complete the project, a final announcement was placed in KState Today, ${ }^{18}$ directing faculty to the Libraries website where the list of cancelled titles could be reviewed. ${ }^{19}$ It is the Libraries' goal to continue developing the cancellations page to provide the university faculty and students with transparent budget trends. It is hoped this information will explicitly demonstrate the trend of budget and resource cuts at the Libraries, and encourage faculty to participate in cancellation projects, even though it is an unpleasant, and perhaps regular, occurrence. It is further hoped such information can be made available to university administration to demonstrate the negative effect of failing to adequately fund the Libraries.

\section{Conclusion, reflection, and future insights}

In the absence of an associate dean for technical services and a content development department head, content development librarians lead a review of major journal packages for potential cancellation. Collaborating with subject specialists and university department faculty, quantitative and qualitative data were merged to make well-informed retention decisions with a high level of transparency on campus. As a result, the completed project cancelled all but one package, choosing to subscribe to a smaller number of selected journals to meet cancellation target goals. Despite the non-renewal of more than 490 journals and reducing the budget by $\$ 128,609.39$ for the fiscal year, prior-year cancellation savings, cuts to the monographs budget, and shifting funds within the Libraries will be necessary to meet the final targeted reduction of $\$ 285,000$. Additional resource cuts will need to be made if inflation figures are higher than predicted, if state money callbacks are implemented, or if the library budget is reduced by the university. It was noted that such cuts may negatively affect curriculum and research support at the university, as even some high use and reputable journals could not be retained.

During the process of the cancellations review, several measures could be instituted to improve the efficiency and standardization of a cancellations project plan. A fire in Hale Library significantly reduced the amount of time to gather quantitative and qualitative statistics. As the Content Development Unit has recently transitioned 
into a Content Development Department, extra administrative support and workflows are being established to proactively conduct reviews with an extended timeframe, enabling greater faculty participation. ${ }^{20}$ It was concluded that summer months are not the optimal time to conduct reviews, as many faculty are not under contract (and unwilling to participate in reviews), conducting research, or preparing for the fall semester. When possible, reviews should be undertaken earlier to avoid such obstacles, potentially generating a higher response rate and more inclusive qualitative data. ${ }^{21}$

Regarding quantitative metrics, given additional time, platforms could be investigated to determine how a single use is calculated, as presented through Counting Online Usage of Networked Electronic Resources reports or other datasets. ${ }^{22}$ It could also provide the opportunity to explore all access options, including journal (and statistical) transfers among publishers. While the Libraries did not have time to add Impact Factors ${ }^{23}$ for journals, some subject specialists looked at Journal Citation Reports to obtain Impact Factors for select titles. The addition of this information could strengthen the decision-making process in future evaluations.

In summation, this project plan established a basis of how to effectively review resources for potential cancellation. As cancellations are likely to continue, the Libraries will monitor interlibrary loan statistics to determine the outcome and any unexpected costs associated with cancellation projects. It is believed that by routinizing data collection, it can be visually presented to university leadership, explicitly illustrating the need for a sustainable library budget to adequately support research and curriculum needs. Until then, this case study has developed a process to ensure future cuts are handled efficiently and fairly, attempting to retain essential resources under times of fiscal scarcity.

Disclosure - No potential conflict of interest was reported by the author.

\section{Notes}

1 "Carnegie Classifications - Listings," The Carnegie Classification of Institutions of Higher Education, http://carnegieclassifications.iu.edu/ (accessed November 01, 2018).

2 Rose, Steve, "Kansas Universities Could Face Budget Axe After State Supreme Court Ruling,” Kansas City Star, Kansas City, MO, June 29, 2018.

3 “Collections Budget Update," Kansas State University Libraries, August 21, 2018. https:// www.lib.kstate.edu/collections-budget. 
4 “Responsibility Centered Management,” Drexel University, https://drexel.edu/rcm/approach/why/ (accessed November 01, 2018).

5 Clarke, Justin, “The Serials Business: Things They May Not Have Covered in Library School," The Serials Librarian 74, no. 1-4 (2018): 65-71.

6 Moisil, Ingrid, "Renew or Cancel? Applying a Model for Objective Journal Evaluation," Serials Review 41 (2015): 160-64.

7 Creswell, John, Research Design: Qualitative, Quantitative, and Mixed Method Approaches (Thousand Oaks: Sage Publications, 2003).

8 Jones, Mary Ann, and Derek Marshall, "Big Deal Deconstruction,” The Serials Librarian 64 (2013): 137-40.

9 Bosch, Stephen, Albee, Barbara, and Kittie Henderson, "Death by 1,ooo Cuts - Periodicals Price Survey 2018," Library Journal, April 23, 2018, https://www.libraryjournal. com/?detailStory=death-1000-cuts-periodicals-price-survey2018\#.

10 Bucknell, Terry, "Garbage in, Gospel Out: Twelve Reasons Why Librarians Should Not Accept Cost-per- Download Figures at Face Value,” The Serials Librarian 63 (2012): 192-212.

11 Hoyt, Sarah McGreer, "In Preparing for Collection Cuts, K-State Libraries Request Feedback From Campus Faculty,” K-State Today, July 16, 2018, https://www.k-state.edu/today/announcement.php?id=42788.

12 “Faculty Demographics,” Kansas State University, https://www.k-state.edu/pa/faculty/ demographics/total/t2018.pdf (accessed January 18, 2019).

13 Bucknell, "Garbage in, Gospel Out."

14 Ibid.

15 Calvert, Kristin, and Rachel Fleming, "Impact of Journal Cancellations on Interlibrary Loan Demand," Serials Review 39 (2013) 184-87.

16 Raymond, Anthony, "Canceling Serials Based on Their Availability in Aggregated FullText Databases," Against the Grain 29, no. 2 (2017): 30.

17 Nixon, Judith, "A Reprise, Or Round Three: Using a Database Management Program as a Decision-Support System for the Cancellation of Serials," The Serials Librarian 59, no. 3-4 (2010): 302-12.

18 "Hoyt, Sarah McGreer, "K-State Libraries Announce Subscription Materials for Nonrenewal,” K-State Today, November 07, 2018, https://www.k-state.edu/today/announcement.php? id $=46368$.

19 “Databases and Serials for Non-Renewal," Kansas State University Libraries, https:// www.lib.k-state.edu/nonrenewal (accessed November 06, 2018).

20 Davis, Hilary M., "Data Informed and Community Driven: Using Data and Feedback Loops to Manage a Journal Review and Cancellation Project," Against the Grain 29, no. 2 (2017): 12; Sapp, Greg, and Peter G. Watson, "Librarian-Faculty Relations During a Period of Journals Cancellations," Journal of Academic Librarianship 15, no. 5 (1989): 285-89.

21 Lindemann, Nigel, "What's the Average Survey Response Rate: 2018 Benchmark," Surveyanyplace.com, April 5, 2018, https://surveyanyplace.com/ average-survey-response-rate/.

22 Bucknell, "Garbage in, Gospel Out."

23 Mosil, "Renew or Cancel?” 


\section{Appendix. Decision Spreadsheet (Qualitative and Quantitative)}

\begin{tabular}{|c|c|c|c|c|c|c|c|c|c|c|c|c|c|c|}
\hline 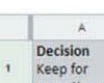 & c & . & $=$ & i & " $x \times$ & costper & & 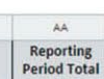 & 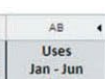 & usgere & $\begin{array}{l}\text { As } \\
\text { Usage }\end{array}$ & Us: & $\mu$ & " \\
\hline & & & & & & & & & & 2017 & 2006 & 2015 & acesses & Notose \\
\hline 2 & & & & & & & & & & & & & & \\
\hline , & & & & & & & & & & & & & & \\
\hline . & & & & & & & & & & & & & & \\
\hline$:$ & & & & & & & & & & - & 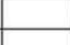 & & & \\
\hline , & & & & & & & & & & & & & & \\
\hline - & & & & & & & & & & & & & & \\
\hline${ }^{\circ}$ & & & & & & & & & & & & & & \\
\hline 10 & & & & & & & & & & 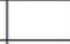 & 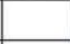 & & & \\
\hline " & & & & & & & & & & & & & & \\
\hline
\end{tabular}

